\title{
Simultaneous Determination of Sodium and Potassium Ions in River Water by Ion Chromatography Using Silica Gels as a Stationary Phase
}

\author{
Tadashi Iwachido*, Kenji Ishimaru** and Shoji Motomizu** \\ * College of Liberal Arts, Okayama University, Okayama 700 \\ **Department of Chemistry, Faculty of Science, Okayama University, Okayama 700
}

\begin{abstract}
Alkali metal cations were shown to be separable on a silica gel column by cation exchange. Factors affecting the separation of these cations were investigated. Among them, type and concentration of the mobile phase electrolytes profoundly affected the retention of the analyte. The alkali metal cations were well separated on a 150 $\mathrm{mm}$ long Zorbax SIL column with $2.1 \mathrm{~mm}$ i.d., using an aqueous $0.01 \mathrm{~mol} \mathrm{dm}^{-3}$ lithium acetate as the mobile phase. Sodium and potassium in river water were determined rapidly with satisfactory accuracy.
\end{abstract}

Keywords Alkali metals, silica gel column, simultaneous determination, sodium, potassium, river water, ion chromatography

Silica gels, which are known as good adsorbents for numerous compounds, have long been used as packing materials in chromatography.' Owing to their rigidity, they are used as polar packings in high performance liquid chromatography. But their most widespread use is as reversed phase packings; for example, silica gels possessing an $n$-octadecyl group bonded via a $\mathrm{Si}-\mathrm{O}-\mathrm{Si}$ linkage to the silica matrix are very popular and versatile.

Recently, we prepared crown ether-modified silica gel columns and studied the chromatographic behavior of alkali metal cations on them. ${ }^{2}$ The elution sequence varied characteristically depending on the crown ether moieties immobilized. The best separation was attained with benzo-18-crown-6 using water as the mobile phase. The analytical application of this method, however, was only a limited one because of its low sensitivity [detection limit: $0.005 \mathrm{M}\left(\mathrm{mol} \mathrm{dm}^{-3}\right)$ ].

The ion exchange ability of silica gels also has long been known but such analytical applications are not so popular as resin-based ion exchangers. ${ }^{3.4}$ Little is known about ion chromatography on silica gels. ${ }^{5}$

This work focuses on the utility of silica gel columns for the ion chromatographic determination of sodium and potassium cations in river water.

\section{Experimental}

\section{Reagents}

Alkali metal chlorides of reagent grade (Merck) were used as received. Alkaline earth salts (Wako) also were of reagent grade. Deionized water was prepared with an Auto Still (Model WAG-28, Yamato). The resulting water was redistilled with an all-quartz-made, non-boiling type distilling apparatus (HF-200, Fujiwara Seisakusho). Aqueous mobile phases were prepared by dissolving the salts in water and were stored in a polyethylene reservoir equipped with a sodium hydroxide column to avoid contamination by carbon dioxide in the air.

\section{Apparatus and procedure}

The apparatus used was an assembly of a solvent delivery pump. (LC-5A and LC-6A, Shimadzu) equipped with a syringe-loading sample injection valve with a $5-\mu l(200-\mu l$ for water samples) loop (Model 7125 , Rheodyne), a conductometric detector (Conductomonitor 701, Laboratory Data Control) and an integrator (3390A, Hewlett-Packard). The column used was a stainless steel tube $(250 \mathrm{~mm}$ long and 4.6 mm i.d.) containing Zorbax SIL (particle size: $5 \mu \mathrm{m}$, Du Pont). A shorter, small bored Zorbax SIL column $(150 \mathrm{~mm} \times 2.1 \mathrm{~mm})$ was used only for the analysis of river water. Operating pressures never exceeded 150 $\mathrm{kg} / \mathrm{cm}^{2}$ at a maximum flow rate of $1.0 \mathrm{ml} / \mathrm{min}$. The temperature of the measuring system was controlled at $25 \pm 0.1^{\circ} \mathrm{C}$. Potassium and sodium in river water were also determined with a polarized Zeeman atomic absorption spectrophotometer (Z-8000, Hitachi).

\section{Results and Discussion}

Ion exchange on the silica gel surface

The surfaces of silica gels and their ion exchange 
properties have been discussed extensively by Unger.' Chromatograms on the silica gel columns are explained by assuming that the surface silanol group acts as an accessible exchange site and undergoes cation exchange reactions as follows:

$$
\begin{aligned}
& -\mathrm{SiO}^{-} \mathrm{H}^{+}+\mathrm{M}^{+}=-\mathrm{SiO}^{-} \mathrm{M}^{+}+\mathrm{H}^{+} \ldots \ldots \ldots \ldots \ldots \ldots \\
& -\mathrm{SiO}^{-} \mathrm{M}^{+}+\mathrm{X}^{+} \leftrightharpoons-\mathrm{SiO}^{-} \mathrm{X}^{+}+\mathrm{M}^{+} \ldots \ldots \ldots \ldots \ldots \ldots
\end{aligned}
$$

where $\mathrm{M}^{+}$denotes the mobile phase cation and $\mathrm{X}^{+}$the analyte cation.

\section{Chromatograms and the peak assignments}

Some typical chromatograms on the silica column using an aqueous $\mathrm{LiCl}$ solution as the mobile phase are depicted in Fig. 1. Chromatogram $1 \mathrm{~A}$ is that for an equimolar mixture of $\mathrm{LiCl}, \mathrm{NaCl}, \mathrm{KCl}, \mathrm{RbCl}$ and $\mathrm{CsCl}$ (test analyte). The four incompletely-resolved peaks were identified in the elution order as follows: $\mathrm{Na}^{+}<\mathrm{K}^{+}<\mathrm{Rb}^{+}<\mathrm{Cs}^{+}$. The order was identical with that reported earlier. ${ }^{3}$ The origin of the observed peaks can be explained as follows: (a) Before the introduction of the test analyte, the exchange sites retain $\mathrm{Li}^{+}$as the counter ion (Eq. 1). When the test analyte is introduced, all the cations are exchanged with equivalent amounts of the $\mathrm{Li}^{+}$on the exchange sites (Eq. 2). (b) $\mathrm{The}^{+} \mathrm{Li}^{+}$originally present in the analyte solution and the liberated ones give the first peak. (c) The analyte cations adsorbed are finally replaced by the $\mathrm{Li}^{+}$in the mobile phase (reverse reaction of Eq. 2), giving a series of the analyte peaks.

The injection of an aqueous $\mathrm{KCl}$ solution yielded chromatogram 1B; the first and second peaks were estimated, in the same way, to be $\mathrm{Li}^{+}$and $\mathrm{K}^{+}$peaks, respectively.

When the analyte anion and the mobile phase anion are different, the chromatograms become complex. Chromatogram $1 \mathrm{C}$ is that for a $\mathrm{K}_{2} \mathrm{SO}_{4}$ solution. To

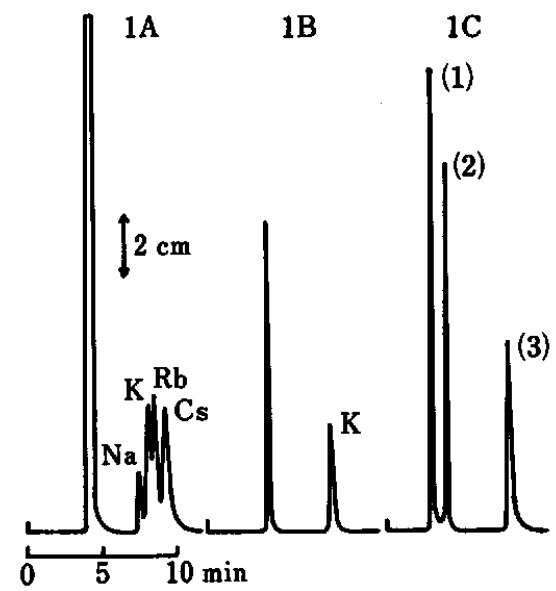

Fig. 1 Typical chromatograms of $0.02 \mathrm{M}$ (A) $\mathrm{LiCl}-\mathrm{CsCl}$ (B) $\mathrm{KCl}$ and (C) $\mathrm{K}_{2} \mathrm{SO}_{4}$ solutions on Zorbax SIL $(250 \mathrm{~mm} \times$ $4.6 \mathrm{~mm}$ i.d.); aqueous $0.01 \mathrm{M} \mathrm{LiCl}$ mobile phase at 0.7 $\mathrm{ml} / \mathrm{min}$. assign peaks (1), (2) and (3), each fraction was collected and then analyzed by a flow injection method $\left(\mathrm{K}^{+}\right)^{6}$ or by ion chromatography (anions). ${ }^{7}$ Peaks (1), (2) and (3) were assigned to $\mathrm{Li}_{2} \mathrm{SO}_{4}, \mathrm{LiCl}$ and $\mathrm{KCl}$, respectively. With regard to the appearance of the former two peaks, further investigation seems needed.

It must be noted that the first peaks in chromatograms $1 \mathrm{~A}$ and $\mathrm{IB}$ and the second one in chromatogram $1 \mathrm{C}$ are observed as a result of the overlapping of the negative peak of water and the positive peak of $\mathrm{LiCl}$.

\section{Effect of the type of the mobile phase electrolytes}

In Fig. 2, chromatograms of the test analyte eluted by aqueous solutions of $\mathrm{LiCl}$ (2A), LiOAc (lithium acetate: 2B), NaOAc (2C), $\mathrm{KOAc}(2 \mathrm{D}), \mathrm{Ca}(\mathrm{OAc})_{2}(2 \mathrm{E})$ are shown. The retention sequence was as follows: $\mathrm{Li}^{+}<\mathrm{Na}^{+}<\mathrm{K}^{+}<\mathrm{Rb}^{+}<\mathrm{Cs}^{+}$. The sequence was not affected by the type of the mobile phase electrolyte. In chromatogram $2 \mathrm{C}, \mathrm{Li}^{+}$in the analyte was detected as a negative peak. $\mathrm{Na}^{+}$, the mobile phase cations, constituted the first peak, and hence they were not detected at their own location (between the $\mathrm{Li}^{+}$and $\mathrm{K}^{+}$peaks). In chromatogram $2 \mathrm{D}, \mathrm{Li}^{+}$and $\mathrm{Na}^{+}$were detected as negative peaks. When $\mathrm{Ca}^{2+}$ was used as the mobile phase cation, the analyte cations were all detected (chromatogram 2E).

Figure 2 also shows that the height and direction of the peaks and the retention vary remarkably according to the mobile phase electrolytes used. The difference in equivalent conductivities between the analyte cations and mobile phase cations greatly affected the height and direction of the peaks. When the conductivity of the analyte cation was similar in magnitude to that of the mobile phase cation, the sensitive detection of the analyte cation was very hard (chromatogram 2D). Thus, the use of $\mathrm{Li}^{+}$, which has the smallest conductivity among the cations under consideration, is

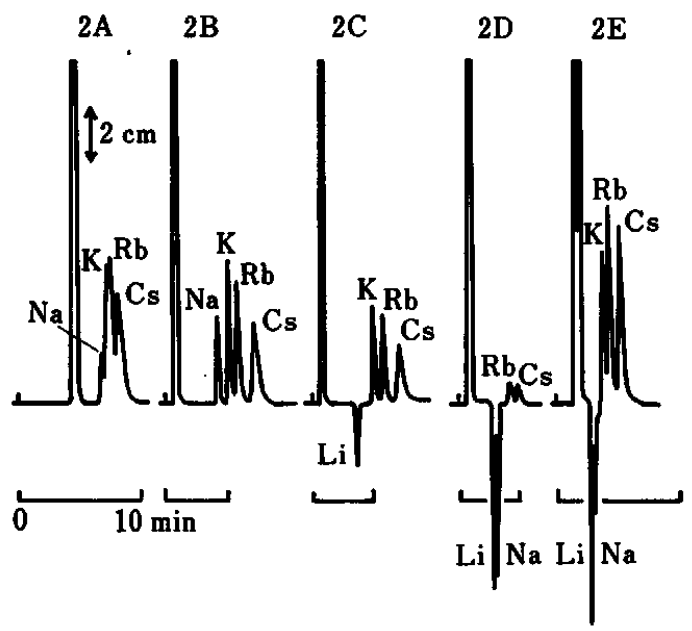

Fig. 2 Separation of $0.01 \mathrm{M}$ alkali metal chlorides on Zorbax SIL (150 mm $\times 4.6 \mathrm{~mm}$ i.d.): aqueous $0.01 \mathrm{M}$ (A) $\mathrm{LiCl}$, (B) LiOAc, (C) NaOAc, (D) KOAc and (E) $\mathrm{Ca}(\mathrm{OAc})_{2}$ mobile phases at $1.0 \mathrm{ml} / \mathrm{min}$. 
recommended as the mobile phase electrolyte for more sensitive detection. Another way to attain high sensitivity is to use stronger mobile phase electrolytes; for example, the use of $\mathrm{Ca}(\mathrm{OAc})_{2}$ mobile phase markedly reduced the retention times and caused a marked increase in the peak heights (chromatogram 2E).

Negative peaks were observed when cations having smaller conductivities than the analyte cations were used as the mobile phase cations. Therefore, the following ion conductivity data in $\mathrm{S} \mathrm{cm}^{2}$ equivil are helpful in predicting the direction of the peaks: $\mathrm{Li}^{+}$ 38.7, $\mathrm{Na}^{+}$50.1, $\mathrm{K}^{+}$73.5, $\mathrm{Rb}^{+}$77.8, $\mathrm{Cs}^{+}$73.6, $\mathrm{NH}_{4}{ }^{+}$73.6; $\mathrm{Mg}^{2+}$ 53.1, $\mathrm{Ca}^{2+}$ 59.5, $\mathrm{Sr}^{2+}$ 59.5, $\mathrm{Ba}^{2+}$ 63.6. ${ }^{8}$

A better peak resolution was obtained when aqueous acetate solutions were used as the mobile phase (compare chromatograms $2 \mathrm{~A}$ with $2 \mathrm{~B}$ ). The enhanced resolution is attributable to an increased ion-exchange capacity of the silica surface $\left[\mathrm{pKa}(-\mathrm{SiOH})=7.1^{\circ}\right]$ due to the increased basicity. It must be noted that the dissolution of silica gel occurs at $\mathrm{pH}>8$.

\section{Ammonium and alkaline earth cations}

An analyte containing $\mathrm{NH}_{4}{ }^{+}$was chromatographed using the acetate mobile phase (chromatograms $3 \mathrm{~A}$ and 3B). The observed retention increased in the order: $\mathrm{Na}^{+}<\mathrm{NH}_{4}{ }^{+}<\mathrm{K}^{+}<\mathrm{Rb}^{+}<\mathrm{Cs}^{+}$. The peak resolution between $\mathrm{NH}_{4}{ }^{+}$and $\mathrm{K}^{+}$was not satisfactory.

The separation of the alkali and alkaline earth metal cations $\left(\mathrm{Mg}^{2+}, \mathrm{Ca}^{2+}, \mathrm{Sr}^{2+}\right.$ and $\left.\mathrm{Ba}^{2+}\right)$ is shown in chromatograms $3 \mathrm{C}, 3 \mathrm{D}$ and $3 \mathrm{E}$. When the $\mathrm{LiCl}$ mobile phase was used, the alkaline earth cations gave a single broad positive peak, as shown in chromatogram 3C. When the KOAc mobile phase was used, they were separated from the alkali metal cations but the

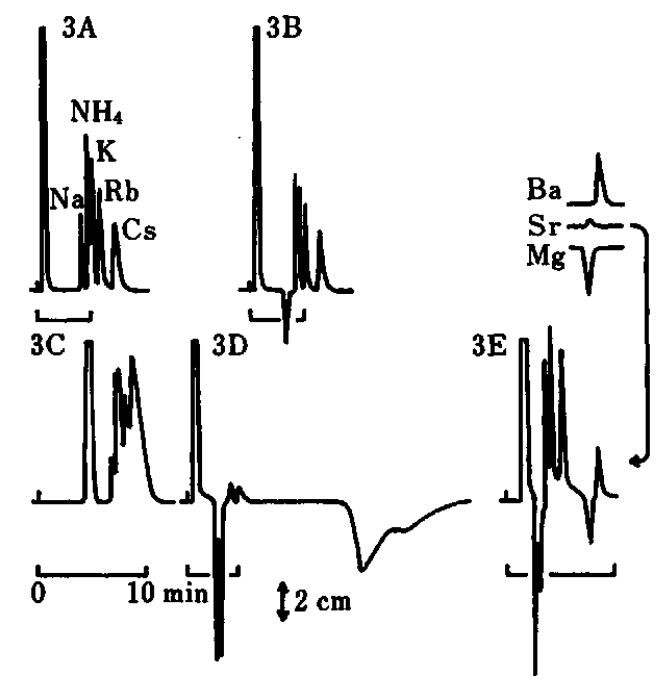

Fig. 3 Separation of $0.01 \mathrm{M}$ alkali metal and ammonium ( $A$ and $B$ ) and $0.01 \mathrm{M}$ alkali and alkaline earth metal chlorides (C. D and E) on Zorbax SIL ( $150 \mathrm{~mm} \times 4.6 \mathrm{~mm}$ i.d.): aqueous $0.01 \mathrm{M}$ (A) LiOAc, (B) $\mathrm{NaOAc}$, (C) $\mathrm{LiCl}$, (D) $\mathrm{KOAc}$ and $(\mathrm{E}) \mathrm{Ca}(\mathrm{OAc})_{2}$ mobile phases at $1.0 \mathrm{ml} / \mathrm{min}$. resolution among them was incomplete. But the use of the $\mathrm{Ca}(\mathrm{OAc})_{2}$ mobile phase yielded two well-separated peaks, as shown in chromatogram 3E, where $\mathbf{M g}^{2+}$ gave a negative peak and $\mathrm{Ba}^{2+}$ a positive one. $\mathrm{A} \mathrm{Sr}^{2+}$ peak was not observed because the conductivity of $\mathrm{Sr}^{2+}$ differs only slightly from that of the mobile phase cations, $\mathrm{Ca}^{2+}$.

\section{Retention of diverse substances}

Table 1 lists the retention times and peak areas for several substances. Pure water exhibited a single negative peak. LiOAc, which is the same electrolyte as the mobile phase, exhibited a single peak though the direction varied from negative to positive as its concentration increased; hence, no peak was necessarily detected when the analyte and mobile phase concentrations were identical. The peak area increased in proportion to the LiOAc concentration. The chromatogram of $\mathrm{NaOAc}$ lacked its anion peak (1st peak) because the analyte anion and the mobile phase anion were common. The analytes, the counter anions of which were different from the mobile phase anions, gave three peaks as mentioned. The areas of the $\mathrm{Na}^{+}$ and $\mathrm{K}^{+}$peaks were determined to be 8 and 24 in arbitrary units. The ratio of the peak areas, $8 / 24$, agreed with that calculated on the basis of the conductivity difference between $\mathrm{Na}^{+}$(or $\mathrm{K}^{+}$) and $\mathrm{Li}^{+}$ $(50.1-38.7) /(73.5-38.7)$.

It is noted that the analyte anions (1st peaks) are

Table 1 Retention times and peak areas of diverse substances $^{\mathbf{a}}$

\begin{tabular}{lclll}
\hline Analyte & Concn./M & 1st peak & 2nd peak & Na/K peak \\
\hline $\mathrm{H}_{2} \mathrm{O}$ & 0 & & $3.87(-11)^{\mathrm{b}}$ & \\
$\mathrm{LiOAc}$ & 0.005 & & $3.90(-8)^{\mathrm{b}}$ & \\
$\mathrm{LiOAc}$ & 0.02 & & $\mathrm{~N} . \mathrm{D}$. & \\
$\mathrm{LiOAc}$ & 0.04 & & $3.87(10)$ & \\
$\mathrm{LiOAc}$ & 0.08 & & $3.95(31)$ & \\
& & & & $\mathrm{Na} \mathrm{peak}$ \\
$\mathrm{NaBr}$ & 0.05 & $3.12(36)$ & $3.89(32)$ & $14.25(9)$ \\
$\mathrm{Nal}$ & 0.05 & $3.11(31)$ & $3.88(25)$ & $14.26(8)$ \\
$\mathrm{NaClO}_{2}$ & 0.05 & $3.15(15)$ & $3.90(29)$ & $14.13(8)$ \\
$\mathrm{NaClO}_{3}$ & 0.05 & $3.12(22)$ & $3.88(26)$ & $14.22(8)$ \\
$\mathrm{NaClO}_{4}$ & 0.05 & $3.10(24)$ & $3.87(25)$ & $14.23(8)$ \\
$\mathrm{NaCN}$ & 0.05 & $3.13(23)$ & $3.90(25)$ & $13.92(8)$ \\
$\mathrm{NaOAc}$ & 0.05 & & $3.92(25)$ & $13.59(7)$ \\
$\mathrm{Na} \mathrm{formate}$ & 0.05 & $3.17(13)$ & $3.91(29)$ & $13.98(8)$ \\
& & & & $\mathrm{K}$ peak \\
$\mathrm{KCl}_{\mathrm{KClO}}$ & 0.05 & $3.15(30)$ & $3.93(28)$ & $15.58(25)$ \\
$\mathrm{KClO}_{4}$ & 0.05 & $3.13(21)$ & $3.90(25)$ & $16.01(24)$ \\
$\mathrm{KNO}_{3}$ & 0.05 & $3.12(23)$ & $3.90(25)$ & $16.09(23)$ \\
$\mathrm{K}_{2} \mathrm{SO}_{4}$ & 0.05 & $3.14(25)$ & $3.91(25)$ & $15.92(23)$ \\
\hline
\end{tabular}

a. Retention time $/$ min (peak area in arbitrary unit); Zorbax SIL. (250 mm $\times 4.6 \mathrm{~mm}$ i.d.); $0.02 \mathrm{M}$ LiOAc mobile phase at 0.7 $\mathrm{ml} / \mathrm{min}$; sample size $5 \mu \mathrm{l}$.

b. Negative peak. 


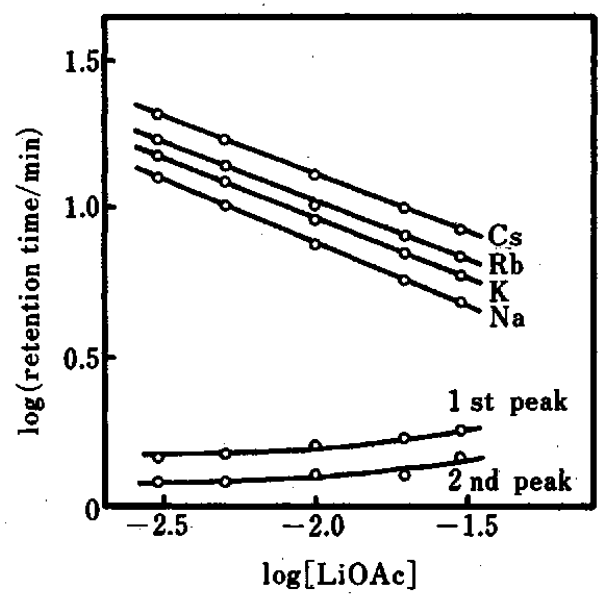

Fig. 4 Retention of $0.01 \mathrm{M}$ alkali metal chlorides on Zorbax SIL ( $150 \mathrm{~mm} \times 4.6 \mathrm{~mm}$ i.d.) as a function of mobile phase concentration: aqueous LiOAc mobile phases at 1.0 $\mathrm{ml} / \mathrm{min}$.

eluted faster than water. The reason is under investigation.

\section{Effect of the mobile phase concentration}

The retention times of the alkali metal cations were measured by varying the concentrations of the mobile phase electrolyte (Fig. 4). The retention times of the first and second peaks increased very slightly, while those due to the analyte cations decreased markedly as the concentration of the mobile phase increased. The peak resolution was little affected by the mobile phase concentration, but the separation between the second peak and the analyte peaks remarkably decreased with an increase in the concentration of the mobile phase electrolyte.

\section{Column maintenance}

A prolonged use of the columns resulted in an accumulation of foreign ions and in a development of a space at the top of the column due to the dissolution of the silica gels. Washing with dilute hydrochloric acid was helpful for the removal of the foreign ions. The development of the space could be recognized by the appearance of an anomalous peak.

\section{Column size}

For practical use, a shorter column is preferred so far as the desired resolution is attainable. To determine an optimal column size, prepacked Zorbax SIL columns of different sizes were prepared (250 $\mathrm{mm} \times 4.6 \mathrm{~mm}$ i.d., $150 \times 4.6$, and $150 \times 2.1)$ and the test analyte was chromatographed on these columns. As the column size decreased, the elution times were reduced, and hence the observed peak height increased. A satisfactory resolution with sufficiently high sensitivity was attained with the shortest column.

Columns containing silica gels from other sources



Fig. 5. Separation of $\mathrm{Na}^{2+}: \mathrm{K}^{+}$mixtures on $150 \mathrm{~mm} \times 2.1$ $\mathrm{mm}$ i.d. Zorbax SIL; an aqueous $0.01 \mathrm{M}$ LiOAc mobile phase at $0.5 \mathrm{ml} / \mathrm{min}$.

(Wakogel LC-5H; $5 \mu \mathrm{m}$, fracture type and LiChrosorb Si 100; $5 \mu \mathrm{m}$, spherical type) were prepared by means of balanced-density slurry method ${ }^{2}$ and the test analyte was chromatographed. The observed peak resolution was poor.

\section{Separation of $\mathrm{Na}^{+}: \mathrm{K}^{+}$mixtures}

To investigate the effect of the relative abundance of $\mathrm{Na}^{+}$to $\mathrm{K}^{+}$on their peak resolution, $200 \mu \mathrm{l}$ of the $\mathrm{Na}^{+}$$\mathrm{K}^{+}$solutions in the listed concentrations (concentration unit: $10^{-5} \mathrm{M}$ ) were introduced (Fig. 5). A large water dip due to a large quantity of water was observed. The peak resolution increased as the amount of minor component increased. However, the errors for the major and minor peaks were less than a few percent. For an equimolar mixture of $\mathrm{K}^{+}$and $\mathrm{NH}_{4}{ }^{+}$, the peak resolution was inferior as expected. The errors for the potassium determination were less than 18 percent. River water ordinarily contains less about $0.02 \mathrm{ppm}$ of $\mathrm{NH}_{4}{ }^{+10}$, so the interference of ammonium ions seems negligible.

\section{Calibration curves}

A peak area $v s$. the analyte $\left(\mathrm{Na}^{+}: \mathrm{K}^{+}=10: 1\right)$ concentration plot exhibited very good straight lines, with correlation coefficients of 0.999 for $\mathrm{Na}^{+}$and $\mathrm{K}^{+}\left[\mathrm{K}^{+}\right.$: $\left.(1-10) \times 10^{-5} \mathrm{M}\right]$. The relative standard deviations for five runs were $0.26 \%$ for $\mathrm{Na}^{+}$and $0.73 \%$ for $\mathrm{K}^{+}$. For more dilute solutions, another calibration curves were prepared in the same way $\left[\mathrm{K}^{+}:(1-10) \times 10^{-6} \mathrm{M}\right]$. The correlation coefficients were 0.999 for $\mathrm{Na}^{+}$and 0.98 for $\mathrm{K}^{+}$. About 0.1 ppm $\mathrm{Na}^{+}$and $\mathrm{K}^{+}$were determinable.

\section{Determination of sodium and potassium in river water}

Water samples were collected from the Asahi river and the Takahashi river and bottled in polyethylene vessels. The tap water has its source in the Asahi river. These samples were filtered through a membrane filter 


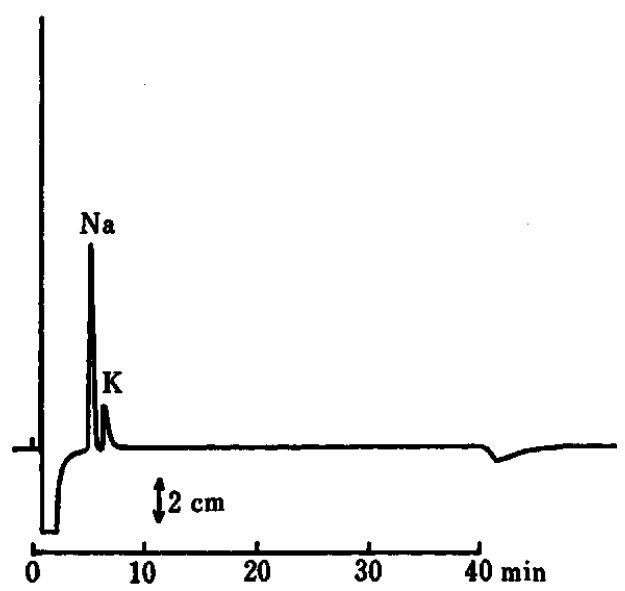

Fig. 6. Typical chromatogram of river water on Zorbax SIL (150 mm $\times 2.1 \mathrm{~mm}$ i.d.): aqueous $0.01 \mathrm{M}$ LiOAc mobile phase at $0.5 \mathrm{ml} / \mathrm{min}$; sample volume, $200 \mu \mathrm{l}$.

Table 2 Sodium and potassium in river water

\begin{tabular}{lcccccc}
\hline Water & \multicolumn{2}{c}{ Sodium, ppm } & & \multicolumn{2}{c}{ Potassium, ppm } \\
\cline { 3 - 4 } & & $\begin{array}{c}\text { Proposed } \\
\text { method }\end{array}$ & AAS & $\begin{array}{c}\text { Proposed } \\
\text { method }\end{array}$ & AAS \\
\hline Asahi river & $\mathrm{A}^{\mathrm{a}}$ & 6.55 & 6.3 & 1.08 & 1.06 \\
& $\mathrm{~B}^{\mathrm{b}}$ & 6.86 & 6.8 & 1.34 & 1.28 \\
Takahashi & & & & & \\
river & $\mathrm{A}^{\mathrm{c}}$ & 8.42 & 9.0 & 1.46 & 1.44 \\
& $\mathrm{~B}^{\mathrm{d}}$ & 7.29 & 7.4 & 1.05 & 1.20 \\
Tap water & & 6.63 & 6.9 & 1.02 & 1.13 \\
\hline
\end{tabular}

a. Okayama-shi. B. Mitsu-cho. c. Kurashiki-shi.

d. Soja-shi.

(pore size: $0.45 \mu \mathrm{m}$, Millipore) and chromatographed as soon as possible. As an illustration, the chromatogram of the Asahi river (A) sample is depicted in Fig. 6. The resolution between $\mathrm{Na}^{+}$and $\mathrm{K}^{+}$ peaks was quite satisfactory. A broad negative peak due to $\mathrm{Mg}^{2+}$ and $\mathrm{Ca}^{2+}$ was observed at $42 \mathrm{~min}$ after the injection. Hence, it was possible to inject four samples at intervals of $8 \mathrm{~min}$; this operation offered much saving in time. The $\mathrm{Na}^{+}$and $\mathrm{K}^{+}$concentrations are shown in Table 2, together with those obtained from atomic absorption spectrophotometry (AAS).

The $\mathrm{Na}^{+}$and $\mathrm{K}^{+}$values obtained by the proposed method showed good agreement with those of AAS. Among the chromatograms observed, two showed a discernible shoulder near the uprising of the potassium peak indicating the presence of very small quantities of ammonium ions.

The proposed method was the most accurate, rapid and convenient one among those developed recently. ${ }^{11,12}$

\section{References}

1. K. K. Unger, "Porous Silica", in "J. Chromatogr. Lib.", Elsevier, Amsterdam (1979).

2. T. Iwachido, H. Naito, F. Samukawa, K. Ishimaru and K. Tôei, Bull. Chem. Soc. Jpn., 59, 1475 (1986).

3. R. L. Smith and D. J. Pietryzk, Anal. Chem., 56, 610 (1984).

4. D. N. Strazhesko, V. B. Strelko, V. N. Belyakov and S. C. Rubanik, J. Chromatogr., 102, 191 (1974).

5. D. L. Dugger, J. J. Stanton, B. N. Irby, B. L. McConnel, W. W. Cummings and R. W. Maatmann, J. Phys. Chem., 68, 757 (1964).

6. T. Iwachido, M. Onoda and S. Motomizu, Anal. Sci., 2, 493 (1986).

7. S. Motomizu, I. Sawatani, T. Hironaka, M. Oshima and K. Tôei, Bunseki Kagaku, 36, 77 (1987).

8. R. A. Robinson and R. H. Stokes, "Electrolyte Solutions", Butterworths, London (1968).

9. M. L. Hair and W. Hertl, J. Phys. Chem., 74, 91 (1970).

10. T. Kuwaki, M. Akiba, M. Oshima and S. Motomizu, Bunseki Kagaku, 36, T81 (1987).

11. T. Iwachido, M. Tajiri and K. Tôei, Bunseki Kagaku, 34, 579 (1985).

12. T. Iwachido, K. Ishimaru and K. Tôei, Bunseki Kagaku, 35, 892 (1986). 